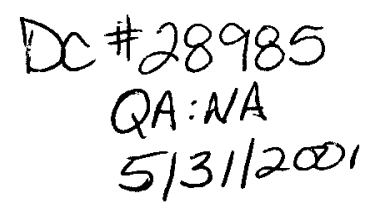

\title{
Simulating Infiltration at the Large-Scale Ponded Infiltration Test, INEEL
}

\section{Research Objectives}

André Unger, Ardyth Simmons, Gudmundur Bodvarsson

MOL . 20010808.0253

This work involved using ITOUGH2 to simulate the Large-Scale Ponded Infiltration Test (LPIT)

at Idaho National Engineering and Environmental Laboratory (INEEL) in order to calibrate parameters controlling the infiltration of water in fractured basalt using a dual-permeability modeling approach. This supports the higher objective of building confidence in the use of the dual-permeability approach for modeling flow and transport in unsaturated fractured rock systems. In particular, the objective of this work is to be able to understand transport of radionuclides at INEEL and subsequently at Yucca Mountain, Nevada.

\section{Approach}

A 3-D dual-permeability mesh representing the geological conditions at the LPIT was constructed as shown by the cross-section on Figure 1a. The geology consisted of surficial sediments, two separate basalt flows (A and B basalts) underlain by a low permeability sedimentary interbed (BC interbed), with a lower $\mathrm{C}$ basalt constituting the bottom of the model. Water was allowed to infiltrate from the pond and then pool on top of the sedimentary interbed. Water pressure and ${ }^{75} \mathrm{Se}$ breakthroughs were simulated at four wells screened within the fractured basalt on top of the sedimentary interbed (B04N11, C04C11, B06N11, C06C11) along two radial angles and at two radial distances. Model results were calibrated to field data using ITOUGH2.

\section{Accomplishments}

Five parameters were selected for calibration by ITOUGH2: basalt fracture continuum permeability, basalt matrix continuum permeability, BC interbed permeability, and BC interbed van Genuchten capillary pressure parameters $\alpha$ and $n$. Inversions were performed using constant fracture-matrix continuum area scaling factors of: $0.02,0.01$ and 0.005 . Results of the calibration to the hydrographs using a fracture-matrix continuum area scaling factor of 0.01 are shown on Figure $1 \mathrm{~b}$ and are: basalt fracture continuum permeability of $3.27 \times 10^{-10} \mathrm{~m}^{2}$, basalt matrix continuum permeability of $2.51 \times 10^{-15} \mathrm{~m}^{2}$, BC interbed permeability of $5.01 \times 10^{-17} \mathrm{~m}^{2}, \mathrm{BC}$ interbed van Genuchten $\alpha$ of $1 \times 10^{-4} \mathrm{~Pa}^{-1}$ and $\mathrm{n}$ of 0.28 .

\section{Significance of Findings}

The significance of this calibration effort pertains to previous modeling efforts conducted at the Box Canyon site at INEEL as well as the use of the dual-permeability modeling approach to simulate steady-state and transient infiltration at Yucca Mountain. Parameters obtained from this modeling effort agree closely with those obtained in a preliminary study conducted at the Box Canyon site. Although the Box Canyon experiment was also conducted in fractured basalt, it consisted of observing infiltration front arrival times within active water conducting features under repeated infiltrated tests at a much smaller scale than the LPIT experiment. Therefore, we conclude that the use of the dual-permeability approach with a constant fracture-matrix continuum area scaling factor is adequate for modeling transient infiltration at a variety of scales and under various wetting histories. Successful application of the dual-permeability modeling approach for simulating the LPIT lends credibility to the use of the same approach for modeling infiltration (both transient and steady state) at the Yucca Mountain site.

\section{Related Publications}

Unger, A.J.A., B. Faybishenko, G.S. Bodvarsson, A.M. Simmons, A three-dimensional model for simulating ponded infiltration tests in the variably saturated fractured basalt at the Box 
Canyon Site, Idaho., Rep. LBNL-44613, Lawrence Berkeley Laboratory, Berkeley, CA., April 2000.

\section{Acknowledgements}

This work was supported by the Director, Office of Civilian Radioactive Waste Management, U.S. Department of Energy, through Memorandum Purchase Order EA9013MC5X between Bechtel SAIC Company, LLC and the Ernest Orlando Lawrence Berkeley National Laboratory (Berkeley Lab). The support is provided to Berkeley Lab through the U.S. Department of Energy Contract No. DE-AC03-76SF00098.

Figure 1: (a) Water saturation in the fracture continuum $\left(S_{\mathrm{wf}}\right) 35.5$ days after the start of the infiltration test and (b) field (symbol) and calibrated model (lines) hydrographs. Note that wells $\mathrm{B} 04 \mathrm{~N} 11$ and $\mathrm{B} 06 \mathrm{~N} 11$ are located at the same radial distance as are $\mathrm{C} 04 \mathrm{C} 11$ and $\mathrm{C} 06 \mathrm{C} 11$ while "04" and "06" wells are on the same radial angle. 


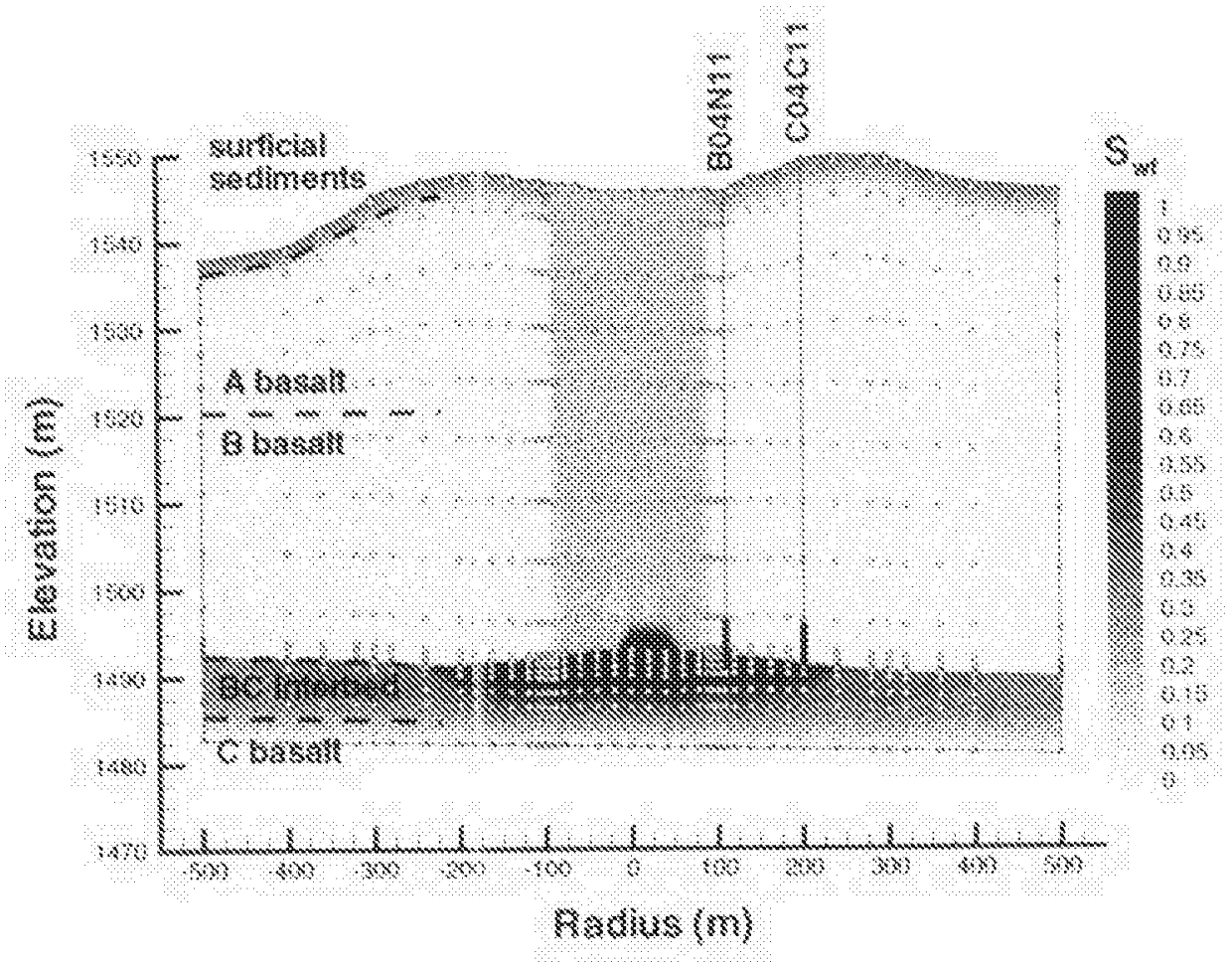




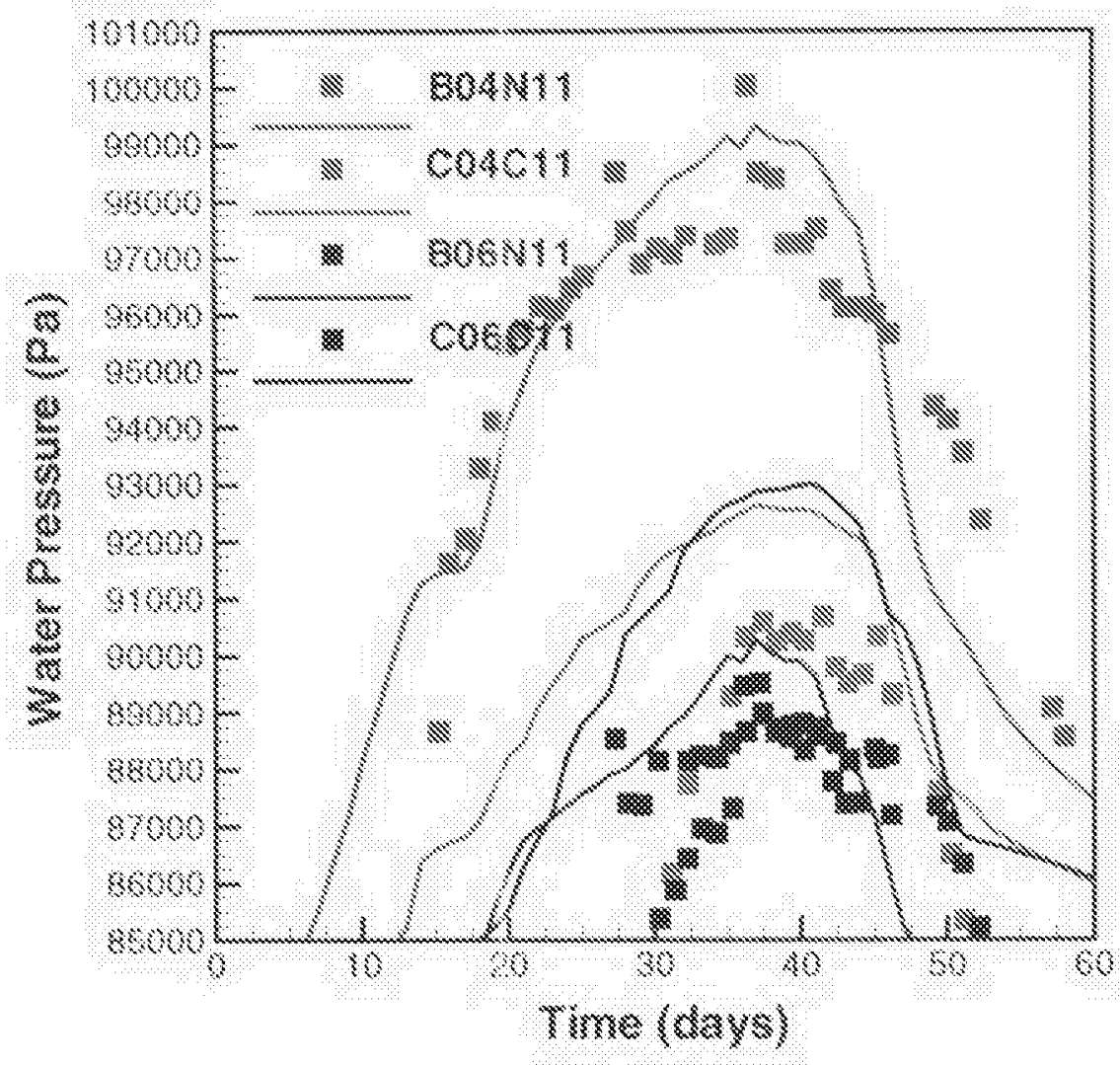

